\title{
Is there correlation between cognition and functionality in severe dementia? The value of a performance-based ecological assessment for Alzheimer's disease
}

Há correlação entre cognição e funcionalidade na demência grave? Utilidade da avaliação ecológica baseada no desempenho para a doença de Alzheimer José R. Wajman, Fabricio F. Oliveira, Sheilla M. C. Marin, Rodrigo R. Schultz, Paulo H. F. Bertolucci

\begin{abstract}
Objective: Besides significant cognitive decline, patients in later stages of Alzheimer's disease (AD) also present global functional impairment, usually reported by their caregivers. This study searched for preserved activities of daily living by investigating correlations among specific instruments for severe dementia with a performance-based functional scale. Method: A sample of 95 moderate to severe AD patients and their caregivers underwent a neuropsychological battery consisting of screening tools, the Functional Assessment Staging Test (FAST), the Severe Mini-Mental State Examination (MMSEsev) and a performance-based ecological scale, the Performance Test of Activities of Daily Living (PADL). Results: Consistent findings emerged from the comparisons among tests. PADL showed significant statistical correlation with MMSEsev $(\rho<0.001)$, according to FAST subdivisions. Conclusion: Upon suspicion of unreliable caregiver reports, ecological scales may be useful for disease staging. Variable degrees of functionality and cognition may be present even in later stages of $A D$, requiring proper assessment.
\end{abstract}

Keywords: Alzheimer disease, neuropsychology, activities of daily living.

RESUMO

Objetivo: Além do significativo declínio cognitivo, pacientes em estágios avançados da doença de Alzheimer (DA) também apresentam prejuízo funcional global. Este estudo investigou atividades de vida diária correlacionando teste específico para a demência grave, com escala funcional baseada no desempenho. Método: 95 pacientes com DA foram submetidos a uma bateria neuropsicológica composta por instrumentos de rastreio, a escala Functional Assessment Staging Test (FAST), o Mini-exame do Estado Mental grave (MEEMg) e escala ecológica baseada no desempenho: a Performance Test of Activities of Daily Living (PADL). Resultados: Achados consistentes emergiram da comparação entre os instrumentos. De acordo com as subdivisões da escala FAST, a PADL apresentou significativa correlação estatística com o MEEMg ( $\rho<0.001)$. Conclusão: Na suspeita de relato pouco confiável por parte do cuidador, escalas ecológicas podem ser úteis no estadiamento da doença. Igualmente à cognição, variados graus de funcionalidade estão presentes mesmo em fases avançadas da DA, exigindo avaliação adequada.

Palavras-chave: doença de Alzheimer, neuropsicologia, atividades de vida diária.

Dementias are a worldwide burden to public health systems. Given the demographic changes with a global aging trend (faster in developing countries), estimates on the rising prevalence of these disorders are discouraging, considering associated costs in primary, secondary and tertiary levels of care ${ }^{1}$. As suggested by current guidelines ${ }^{2}$, the progressive course of dementia might be classified in three main stages: mild - there is still some aptitude for independent life, despite the impact on instrumental activities of daily living; moderate - the abilities for independent living are limited and supervision is needed in many activities; severe restricted independence for all activities, including personal hygiene, limited language skills, sometimes with mutism, and often apathy.

Departamento de Neurologia e Neurocirurgia, Escola Paulista de Medicina, Universidade Federal de São Paulo, Sao Paulo SP, Brazil. Correspondence: José Roberto Wajman; Rua Itapeva, 518 / Salas 401-402; 01332-904 São Paulo SP; Brasil; E-mail: jrwajman@gmail.com Conflict of interest: There is no conflict of interest to declare. 
Along the progression of Alzheimer disease ( $\mathrm{AD}$ ), even basic activities and social interaction become increasingly impaired $^{3,4}$. Concerning executive functions, for instance, a progressive deficit that also makes evaluation of cognitive functions more difficult may be present ${ }^{5}$. There is some skepticism in evaluating cognition and functionality in severe stages of dementia. Furthermore, the nature of the relationship between real life activities of daily living (ADLs) and neuropsychological performance has yet to be fully delineated. For this purpose, some studies have used informant-based measures to assess functional status ${ }^{6}$, but only a few used a performance-based measure, in which the patient is actually observed and objectively rated on his or her ability to perform various ADLs; ${ }^{7}$ yet, no such study has ever been conducted with moderate, moderately severe, and severe $\mathrm{AD}$ patients.

In view of the scarcity of specific instruments that precisely evaluate cognitive and (performance-based) functional abilities of these persons, the main objective of the present study was to search for preserved activities of daily living by investigating correlations among specific instruments for severe dementia with a performance-based functional scale, proposing a short and accessible neuropsychological battery for public health care services.

\section{METHOD}

\section{Sample}

For this research, 95 male and female subjects with moderate, moderately severe and severe $\mathrm{AD}$ and their caregivers were consecutively included between December 2008 and January 2012. All subjects were followed by a multidisciplinary team consisting of three clinical neurologists, a neuropsychologist and a speech therapist at the Behavioral Neurology Outpatients Clinic of Hospital Sao Paulo, Federal University of Sao Paulo. All patients met Diagnostic and Statistical Manual of Mental Disorders DSM-IV ${ }^{2}$ diagnostic criteria for probable AD. For inclusion in the study protocol, each patient should score between five and fifteen points (5-15) on the traditional Mini-Mental State Examination - MMSE ${ }^{8}$, and be on stages 2.0 or 3.0 of the Clinical Dementia Rating scale - CDR?

We excluded patients who did not spend time with the same caregiver at least four daily hours for at least four days per week, patients who had any uncorrected visual or auditory deficits that could affect their evaluation (inadequate or unsuited prostheses), and patients with history of cerebrovascular diseases (ischemic or hemorrhagic strokes) in the 12 months preceding the neuropsychological assessment.

This study was approved by the Ethics Committee of the Federal University of Sao Paulo (Registration 1373/09). An Informed Consent was read to all subjects and their caregivers before they signed it, and doubts were discussed at any time during the study.

\section{Instruments and Procedure}

Regarding screening for cognition, we employed the $\mathrm{MMSE}^{8}$ and, for an accurate stratification of disease staging, the Functional Assessment Staging Test - FAST ${ }^{10}$ (a rating scale comprising cognitive and functional items developed for grading severe dementia).

For specific cognitive evaluation, we employed the Severe Mini-Mental State Examination - MMSEsev ${ }^{11,12}$. The MMSEsev is based on the original version of the MMSE ${ }^{8}$, but with simpler questions, including self-recognition, orientation, responding to simple commands, constructive skills, semantic verbal fluency, and memory. Scores range from 0 to 30, like the original test, and the mean time for application ranges from 5 to 10 minutes.

For comparisons of cognitive scales with functionality, the Performance Test of Activities of Daily Living - PADL ${ }^{13}$ was employed. It was initially developed for self-care evaluations at geriatric psychiatric patients. This scale assesses objective behavioral skills by way of 16 elementary and minor complex activities of daily life. It is a structured performance test requiring patients to objectively demonstrate their abilities for selected activities of daily living, such as filling a glass of water and drinking it, making a phone call, shaving and applying makeup, among others. Observation of the actual performance in a clinical setting requires common items like a glass, a box of tissue paper, a comb or hair brush, a nail-file, a spoon, a wall clock, a telephone, paper and pencil, demanding awareness of safety (e.g. turning a light switch on and off). Scores range from 0 (not completely done) and 1 (correctly done) to 9 (unable), and it takes around 20 minutes to be completed. Thus, the PADL categorizes patients into different levels of functional independence by way of the administration of tasks related to basic and instrumental activities of daily living. Most tasks include the manipulation of props, which can be assembled into a portable kit and administered in remote settings.

An interview to collect personal data was the first step of the assessment followed by the application of screening scales, and then the complete neuropsychological battery. Whenever fatigue, anxiety or nervousness were noticed the test was interrupted, the subject was reassured, and the testing proceeded on only after the subject calmed down, considering the possibility of postponing the end of the assessment for another visit. The assessment for each patient took around one hour to be completed.

\section{Statistical analysis}

Initially, statistical analysis was conducted by way of a descriptive statistic with mean, median and square deviation for quantitative variables that were put in dispersion 
graphics and box plots. Furthermore, qualitative variables were analyzed by way of absolute and relative frequency calculations.

Inferential analyses were undertaken to confirm or refute evidences raised by the descriptive analysis. Pearson's intervalar and point estimation ${ }^{14,15}$ were performed to quantify the linear relationship between a variable and a constant. Results from the PADL and the MMSEsev were correlated according to FAST stages using Kruskal-Wallis test and ANOVA as a fixed factor.

For all conclusions obtained by inferential analysis, the threshold of significance was set at $\rho<0.05$.

\section{RESULTS}

A total of 95 patients with advanced $\mathrm{AD}$ were included. Among them, mean age was $74.7 \pm 6.2$ years-old, mean schooling was $4.2 \pm 1.5$ years, mean disease duration was $7.3 \pm 1.7$ years, and most patients were female (65.3\%). The mean MMSE score was $9.6 \pm 3.0$, and $76.8 \%$ of the patients were severely impaired $(\mathrm{CDR}=3.0)$. Mean PADL score was 9.6 \pm 3.2 (median 9.0), ranging from 5.0 (minimum) to 16.0 (maximum). Results can be seen in Table 1.

The inferential results demonstrated that the sample distribution between the three different categories of FAST (moderate: 5, moderately severe: 6 and severe: 7) showed particular patterns at MMSEsev final scores. When test scores were compared with each other, individuals with FAST in the moderate stage (stage 5) showed positive statistical correlation $(\rho=0.002)$. Individuals with FAST in the moderately severe stage (stage 6), representing $54.7 \%$ of the total sample, had a significant correlation with PADL, considering the results obtained on MMSEsev $(\rho<0.001)$. Once comparing severe FAST patients (stage 7 ) with moderately severe dementia, a significant statistical correlation was also verified between PADL and MMSEsev $(\rho=0.002)$. Details of these results are shown in Table 2.

Figure 1 presents the joint distribution of PADL and MMSEsev scores. In this sense, in agreement with estimates of the linear correlation coefficients of Pearson $(r)$, we observe a statistically significant correspondence between PADL and the MMSEsev ( $R=0.322, \rho=0.001)$, suggesting that the performance-based tool (PADL) is positively and significantly correlated to the specific cognitive measure for severe dementia (MMSEsev).

Results of the analysis of variance (ANOVA) within each of the FAST subcategories were significant $(\rho<0.001)$ with regard to the ecological functional scale taken as the measure to be tested (PADL) and the specific cognitive test for severe dementia (MMSEsev). Nevertheless, Figure 2 shows a boxplot illustration of the convergent progression of PADL scoring according to stratified FAST (5 to 7B), demonstrating a linear decrease according to the evolution of the disease, suggesting a statistical correlation between cognitive and functional decline.

Table 1. Neuropsychological test results.

\begin{tabular}{|c|c|c|c|}
\hline Neuropsychological test & Test parameter or score & $n$ & $\%$ or value \\
\hline \multirow[t]{2}{*}{ CDR } & 2.0 (moderate dementia stage) & 22 & $23.2 \%$ \\
\hline & 3.0 (severe dementia stage) & 73 & $76.8 \%$ \\
\hline \multirow[t]{3}{*}{ FAST } & moderate (5) & 16 & $16.8 \%$ \\
\hline & moderately severe (6) & 52 & $54.7 \%$ \\
\hline & severe (7) & 27 & $28.4 \%$ \\
\hline \multirow[t]{6}{*}{ FAST } & 5 & 16 & $16.8 \%$ \\
\hline & $6 \mathrm{~A}$ & 21 & $22.1 \%$ \\
\hline & $6 \mathrm{~B}$ & 15 & $15.8 \%$ \\
\hline & $6 C$ & 16 & $16.8 \%$ \\
\hline & $7 \mathrm{~A}$ & 15 & $15.8 \%$ \\
\hline & $7 \mathrm{~B}$ & 12 & $12.6 \%$ \\
\hline \multirow[t]{4}{*}{ MMSE } & mean & - & 9.6 \\
\hline & median & - & 10.0 \\
\hline & minimum-maximum & - & $5.0-15.0$ \\
\hline & standard deviation & - & 3.0 \\
\hline \multirow[t]{4}{*}{ MMSEsev } & mean & - & 20.7 \\
\hline & median & - & 21.0 \\
\hline & minimum-maximum & - & $12.0-30.0$ \\
\hline & standard deviation & - & 4.2 \\
\hline \multirow[t]{4}{*}{ PADL } & mean & - & 9.6 \\
\hline & median & - & 9.0 \\
\hline & minimum-maximum & - & $5.0-16.0$ \\
\hline & standard deviation & - & 3.2 \\
\hline
\end{tabular}

CDR: clinical dementia rating; FAST: functional assessment staging test); MMSE: mini-mental state examination; MMSEsev: severe mini-mental state examination; PADL: performance activities of daily living. 
Table 2. Correlations between neuropsychological test results and stratified Functional Assessment Staging Test (FAST).

\begin{tabular}{|c|c|c|}
\hline FAST & PADL & MMSEsev \\
\hline \multicolumn{3}{|l|}{5} \\
\hline N & 16 & 16 \\
\hline mean & 13.6 & 24.1 \\
\hline median & 13.5 & 23.0 \\
\hline minimum-maximum & $11.0-16.0$ & $21.0-30.0$ \\
\hline standard deviation & 1.7 & 3.4 \\
\hline \multicolumn{3}{|l|}{$6 \mathrm{~A}$} \\
\hline N & 21 & 21 \\
\hline mean & 11.6 & 22.0 \\
\hline median & 12.0 & 21.0 \\
\hline minimum-maximum & $9.0-14.0$ & $17.0-29.0$ \\
\hline standard deviation & 1.7 & 3.7 \\
\hline \multicolumn{3}{|l|}{$6 \mathrm{~B}$} \\
\hline N & 15 & 15 \\
\hline mean & 9.7 & 18.7 \\
\hline median & 10.0 & 17.0 \\
\hline minimum-maximum & $5.0-13.0$ & $16.0-24.0$ \\
\hline standard deviation & 2.6 & 3.2 \\
\hline \multicolumn{3}{|l|}{$6 \mathrm{C}$} \\
\hline N & 16 & 16 \\
\hline mean & 7.8 & 21.8 \\
\hline median & 8.0 & 21.5 \\
\hline minimum-maximum & $5.0-11.0$ & $12.0-30.0$ \\
\hline standard seviation & 1.8 & 5.2 \\
\hline \multicolumn{3}{|l|}{$7 \mathrm{~A}$} \\
\hline N & 15 & 15 \\
\hline mean & 6.6 & 17.0 \\
\hline median & 7.0 & 16.0 \\
\hline minimum-maximum & $5.0-9.0$ & $14.0-21.0$ \\
\hline standard deviation & 1.2 & 2.3 \\
\hline \multicolumn{3}{|l|}{$7 \mathrm{~B}$} \\
\hline N & 12 & 12 \\
\hline mean & 6.8 & 19.9 \\
\hline median & 6.0 & 21.0 \\
\hline minimum-maximum & $5.0-15.0$ & $17.0-23.0$ \\
\hline standard deviation & 2.7 & 2.3 \\
\hline $\mathrm{p}$ & $<0.001^{\mathrm{b}}$ & $<0.001^{a}$ \\
\hline
\end{tabular}

aKruskal-Wallis testand; ${ }^{\mathrm{A} A N O V A}$ as a fixed factor. MMSE: mini-mental state examination; PADL: performance activities of daily living; N: number.

\section{DISCUSSION}

Our findings suggest a significant correlation between ecological measure and the Severe Mini-Mental State Examination for severely impaired $\mathrm{AD}$ patients and, to the best of our knowledge, this is the first Brazilian and South American study to ever investigate ADLs in later stages of $\mathrm{AD}$ from an ecological perspective. Beyond that, this study sought to evaluate the aspects of the PADL stratification combined with FAST subdivisions. Briefly, it can be concluded that there was a meaningful relationship among the PADL test results when compared with the MMSEsev evidencing a related progression with regard to the gradual evolution of the disease.

The main purpose for correlating cognitive tools (appropriately weighted by specifically developed instruments for

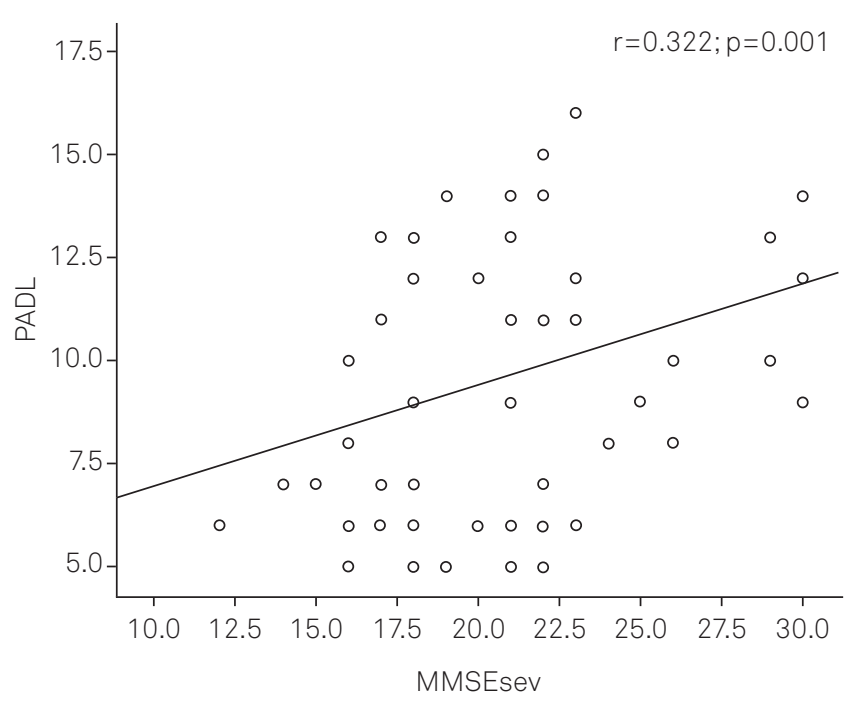

Figure 1. Joint distribution of PADL (performance activities of daily living) and MMSEsev (severe Mini-Mental State

Examination) scores.

moderate and severe stages of dementia) with functional scales, which were intentionally chosen for their psychometric structure is because CDR and FAST are considered "static" (or categorical) scales, whereas in applying PADL, objective aspects that simulate some tasks of everyday life that the subject does in an ecological environment are evaluated.

Scientific studies employing specific tools for severe dementia are scarce, especially in Latin America. Considering the factors that could affect survival in $\mathrm{AD}$, there is no available instrument for prospectively monitoring neuropsychological changes in later stages of this dementia syndrome $^{16}$. From a psychometric perspective, there is an

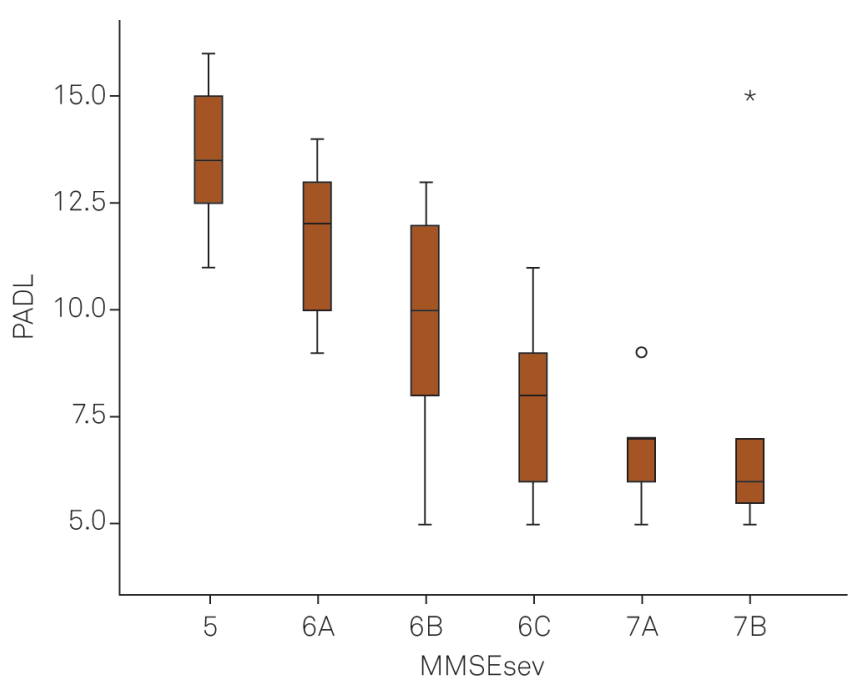

$\mathrm{O}=$ one possible outlier at the 7A FAST stage

* = one probable heavy-tailed value at the 7B FAST stage

Figure 2. PADL (performance activities of daily living) boxplot according to stratified FAST (functional assessment staging test). 
usual rate of progression which is frequently measured by one instrument exclusively through quantitative rating. Nevertheless, most studies employ superficial screening tests and rarely monitor functionality or qualitative aspects in these patients ${ }^{17,18,19}$.

The results of this study may direct future developments with regard to specific techniques to deal with moderately and severely impaired AD patients. The performance-based approach usually requires patients to perform the particular activity under the observation of the examiner. Performancebased assessments have the advantage of objectively assessing functionality in a level that is required for daily living. In this sense, studies have shown that performance-based measures of functional status tend to be more strongly associated with neuropsychological accomplishment than informant-based functional measures ${ }^{20,21}$.

Strengths and limitations of this study need to be described. Patients were recruited from a single center, and while taking into account the complexity of objective assessments of cognition in later dementia stages, results may not be generalizable to all elderly Brazilians with advanced AD. Additionally, in view of the lack of standardized neuropsychological instruments for these patients, it is understood that further studies should be conducted with different samples using alternative measures, with the aim to find the same correlations or new results through the application of different statistical techniques.

Despite these limitations, the current research achieved significant results in investigating preserved activities of daily living (even some basic instrumental abilities) in severely impaired patients. As a rule, functional measures are not fully accurate to resemble the actual behavior of patients in the real world. Likewise, there are also some weaknesses associated with the use of performance-based measures. Nonetheless, there is an important difference between performing an activity proposed by a rater-facilitator in an outpatient setting versus the spontaneous behavior while performing some activities of daily living in the home environment ${ }^{22}$.

Finally, once adopted as the instrument to be tested (or a "gold standard" measure) for the present research, PADL results presented here have shown an accurate correlation with cognitive tests that are reliable in the neuropsychological evaluation of patients in moderate and severe stages of $\mathrm{AD}$. In conclusion, the findings of this study suggest that the ecological functional assessment is a well-grounded alternative for objectively following and assessing the functional status of $\mathrm{AD}$ patients, beyond the reporting of caregiver. Thus, the incorporation and enforcement of instruments such as the one we have proposed can be of paramount importance for clinical and multidisciplinary teams to better understand the symptoms in these stages of the disease $\mathrm{e}^{23}$, as well as to propose proper therapeutic alternatives $^{24}$.

\section{Acknowledgments}

The authors thank all patients and their families or legal caregivers for agreeing to participate on the study.

\section{References}

1. Jonsson B, Jonsson L, Wimo A. Cost of dementia. In: May M, Sartorius N, editors. Dementia: WPA series evidence and experience in psychiatry. London: John Wiley \& Sons; 2000. p. 335-63.

2. American Psychiatric Association. Diagnostic and statistical manual of mental disorders. 4th ed. Washington: American Psychological Association; 1994

3. Tariot PN. Medical management of advanced dementia. J Am Geriatr Soc. 2003;51(5 Suppl Dementia):305-13. http://dx.doi.org/10.1046/ j.1532-5415.5156.x

4. Burns A, Spiegel R, Quarg P. Efficacy of rivastigmine in subjects with moderately severe Alzheimer's disease. Int J Geriatr Psychiatry. 2000;19(3):243-9. http://dx.doi.org/10.1002/gps.1058

5. Lezak MD. Memory I: tests. In: Lezak MD, Howieson DB, Loring DW, editors. Neuropsychological assessment. New York: Oxford University Press; 1995. p. 429-98

6. Searight RH, Dunn EJ, Grisso T, Margolis RB, Gibbons JL. The relation of the Halstead-Reitan neuropsychological battery to ratings of everyday functioning in a geriatric sample. Neuropsychology. 1989;3(3):135-45. http://dx.doi.org/10.1037//0894-4105.3.3.135

7. Nussbaum PD, Goreczny A, Haddad L. Cognitive correlates of functional capacity in elderly depressed versus patients with probable Alzheimer's disease. Neuropsychol Rehabil. 1995;5(4):333-40. http:// dx.doi.org/10.1080/09602019508401476
8. Folstein MF, Folstein SE, McHugh PR. "Mini-mental state": a practical method for grading the cognitive state of patients for the clinician. J Psychiatr Res. 1975;12(3):189-98. http://dx.doi.org/ 10.1016/0022-3956(75)90026-6

9. Morris JC. The Clinical Dementia Rating (CDR): current version and scoring rules. Neurology. 1993;43(11):2412-4. http://dx.doi.org/10.1212/ wnl.43.11.2412-a

10. Reisberg B. Functional assessment staging (FAST). Psychopharmaco Bull. 1998;24(4):653-59.

11. Harrell LE, Marson D, Chatterjee A, Parrish JA. The severe minimental state examination: a new neuropsychologic instrument for the bedside assessment of severely impaired patients with Alzheimer disease. Alzheimer Dis Assoc Disord. 2000;14(3):168-75. http://dx. doi.org/10.1097/00002093-200007000-00008

12. Wajman JR, Bertolucci PHF. Comparison between neuropsychological instruments for severe dementia. Arq Neuropsiquiatr. 2006;64(3B): 736-40. http://dx.doi.org/10.1590/s0004-282x2006000500007

13. Kuriansky JA, Gurland B. The performance test of sctivities of faily living. Int J Aging Hum Dev. 1976;7(4):343-52. http://dx.doi.org/ 10.2190/x45l-tww7-wxxy-ka6k

14. Bussab WO, Morettin PA. Estatística básica. 5a ed. São Paulo: Saraiva; 2006.

15. Altman DG, Machin D, Bryant TN, Gardner MJ. Statistics with confidence. 2 a ed. New York: John Wiley \& Sons; 2000. 
16. Burns A, Lewis G, Jacoby R, Levy R. Factors affecting survival in Alzheimer's disease. Psychol Med. 1991;21(2):363-70. http://dx.doi. org/10.1017/s0033291700020468

17. Doraiswamy PW, Bieber F, Kaiser L, Krishnan KR, Reuning-Scherer J, Gulanski B. The Alzheimer's disease assessment scale: patterns and predictors of baseline cognitive performance in multicenter Alzheimer's disease trials. Neurology. 1997;48(6):1511-7. http://dx.doi. org/10.1212/wnl.48.6.1511

18. Franssen EH, Kluger A, Torassian CL. The neurologic syndrome of severe Alzheimer's disease. Arch Neurol. 1993;50(10):1029-39. http:// dx.doi.org/10.1001/archneur.1993.00540100024010

19. Sakamoto M, Ando H, Tsutou A. Comparing the effects of different individualized music interventions for elderly individuals with severe dementia. Int Psychogeriatrics. 2013;25(5):775-84. http://dx.doi.org/ $10.1017 /$ S1041610212002256

20. Farias ST, Harrel E, Neumann C, Houtz A. The relationship between neuropsychological performance and daily functioning in individuals with Alzheimer's disease: ecological validity of neuropsychological tests. Arch Clin Neuropsychology. 2003;18(6):655-72. http://dx.doi. org/10.1093/arclin/18.6.655

21. Cummings J, Gould H, Zhong K. Advances in designs for Alzheimer's disease clinical trials. Am J Neurodegener Dis. 2012;1(3):205-16.

22. Richardson ED, Nadler JD, Malloy PF. Neuropsychologic predictors of performance measures of daily living skills in geriatric patients. Neuropsychology. 1995;9(4):565-72. http://dx.doi.org/10.1037//08944105.9.4.565

23. Wajman JR, Oliveira FF, Schultz RR, Correia SM, Bertolucci $\mathrm{PH}$. Educational bias in the assessment of severe dementia: Brazilian cutoffs for severe Mini-Mental State Examination. Arq Neuropsiquiatr. 2014;72(4):273-77. http://dx.doi.org/10.1590/0004-282X20140002

24. De Oliveira FF, Bertolucci PHF, Chen ES, Smith MAC. Pharmacological modulation of cognitive and behavioral symptoms in patients with dementia due to Alzheimer's disease. J Neurol Sci. 2014;336(1-2):103-8. http://dx.doi.org/10.1016/j.jns.2013.10.015 